\title{
The Role of the Pterional Approach in the Surgical Treatment of Olfactory Groove Meningiomas: A 20-year Experience
}

\author{
Andrej D. Bitter ${ }^{1}$ Lampis C. Stavrinou ${ }^{2}$ Georgios Ntoulias ${ }^{1} \quad$ Athanasios K. Petridis $^{1}$ Morina Dukagjin ${ }^{1}$ \\ Martin Scholz ${ }^{1}$ Werner Hassler ${ }^{1}$
}

${ }^{1}$ Department of Neurosurgery, Klinikum Duisburg, Duisburg NRW, Germany

2 Department of Neurosurgery, Evangelisches Krankenhaus Bielefeld,

Address for correspondence Athanasios K. Petridis, MD, Department of Neurosurgery, Wedau Kliniken Duisburg, Zu den Rehwiesen 9, Bielefeld NRW, Germany

J Neurol Surg B 2013;74:97-102.

\begin{abstract}
\section{Keywords}

- pterional approach

- olfactory groove meningiomas

- surgical treatment

- meningioma removal

Background Olfactory groove meningiomas remain surgically challenging. The common microsurgical approaches suffer from late exposure of the neurovascular structures. Conversely, the pterional approach has the advantage of early dissection of the posterior neurovascular complex.

Methods We reviewed the records of patients treated for olfactory groove meningioma in our department between 1991 and 2010. A total of 61 patients underwent removal of olfactory groove meningiomas via the pterional approach. These included 58 primary and 3 recurrent tumors. Mean overall follow-up time was 122 months.

Results Early exposure and dissection of the internal carotid artery, middle cerebral artery, anterior cerebral artery, and optic nerve was feasible in all cases. Complete tumor removal was achieved in 60 patients. Morbidity and mortality rates were $26 \%$ and $1.6 \%$ respectively. Postoperative complications included epileptic seizures (five patients) and cerebrospinal fluid (CSF) leak (two patients). During follow-up, we recorded three tumor recurrences.

Conclusions The pterional approach appears to be an excellent solution for the treatment of olfactory groove meningiomas. Its foremost advantage is early visualization of the posterior neurovascular complex. Moreover, it allows frontal sinus preservation and timely tumor devascularization and avoids excessive brain retraction. The pterional view is familiar to most neurosurgeons and therefore the transition to this technique is fairly straightforward.
\end{abstract}

\section{Introduction}

Olfactory groove meningiomas comprise 4.5 to $18 \%$ of all intracranial meningiomas. ${ }^{1,2}$ They commonly present with anosmia, urinary incontinence, visual deficits, seizures, and mental status changes. These symptoms, however, are nonspecific and usually appear late, when the tumor has already reached a significant size. ${ }^{3}$ Moreover, their proximity to important neurovascular structures such as the optic nerves, the internal carotid artery, and the anterior cerebral artery, as well as the potential invasion of the frontal skull base, makes their complete removal troublesome. ${ }^{4}$

The variability of the proposed approaches reflects the surgical challenge the neurosurgeon has to face when treating olfactory groove meningiomas; from the historical bifrontal craniotomies with bilateral partial lobectomy proposed by Cushing and Dandy in 1938 to the current state-of-the-art received

June 26, 2012

accepted after revision

October 19, 2012

published online

January 22, 2013 (c) 2013 Georg Thieme Verlog KG Stuttgart . New York
DOI http://dx.doi.org/ 10.1055/s-0033-1333618. ISSN 2193-6331. 
microsurgical and endoscopical approaches, there is a continuing debate as to the optimal treatment strategy of such lesions. ${ }^{5-7}$ Among this sizeable array of surgical approaches, the most commonly used nowadays are the subfrontal approach, the interhemispheric approach, the supraorbital keyhole approach, and the pterional approach. ${ }^{4,6,8-10}$ Other surgical corridors such as the cranio-orbitozygomatic and the transbasal, as well as the various endoscopic techniques, have passionate advocates and undeniable advantages; their application, however, is rather limited. ${ }^{11-13}$

In this study we present our 19-year experience with the pterional craniotomy for the surgical treatment of olfactory groove meningiomas in a series of 61 patients and discuss its potential advantages over the other commonly used microsurgical approaches.

\section{Patients and Methods}

In a retrospective study, we reviewed the medical charts, neuroimaging data, and follow-up data of patients treated microsurgically for olfactory groove meningioma in our department between January 1991 and October 2010. In this time period, a total of 61 patients ( 21 men and 40 women) 20 to 80 years old (mean: 60 years) underwent microsurgical removal of their olfactory groove meningiomas via the pterional approach. These included 58 primary and 3 recurrent tumors (operated primarily at another institution). Tumor size varied from small (up to $2 \mathrm{~cm}, 5 \%$ of patients) to large ( 2 to $4 \mathrm{~cm}, 6.5 \%$ of patients) and very large $(>4 \mathrm{~cm}, 88.5 \%$ of patients). A compression of the optic apparatus was evident in four patients and invasion of the orbital wall was evident in one patient; three patients had radiological evidence of tumor invasion into the ethmoidal air cells. The most com-

Table 1 Prominent Presenting Symptom at the Time of Diagnosis

\begin{tabular}{|l|l|}
\hline Symptom & $\begin{array}{l}\text { Number of patients } \\
(\mathbf{N}=61)\end{array}$ \\
\hline Anosmia or hyposmia & $30(49.2 \%)$ \\
\hline Visual loss & $22(36 \%)$ \\
\hline Headache & $18(29.5 \%)$ \\
\hline Vertigo & $4(6.5 \%)$ \\
\hline Depression & $4(6.5 \%)$ \\
\hline Aphasia & $1(1.6 \%)$ \\
\hline Epileptic seizure & $5(8.2 \%)$ \\
\hline Exophthalmos & $1(1.6 \%)$ \\
\hline Nausea & $2(3.3 \%)$ \\
\hline Tinnitus & $1(1.6 \%)$ \\
\hline Gait disturbance & $2(3.3 \%)$ \\
\hline Exhaustion & $3(4.9 \%)$ \\
\hline Apathy & $6(9.8 \%)$ \\
\hline Aggressiveness & $6(9.8 \%)$ \\
\hline Psychoorganic syndrome & $16(26.2 \%)$ \\
\hline
\end{tabular}

mon presenting symptom was anosmia (30 patients, 48\%), followed by visual disturbances (22 patients, 36\%), headache (18 patients, $29.5 \%$ ), and psycho-organic syndrome (16 patients, $26.2 \%$ ), expressed by a constellation of clinical manifestations. A complete list of the presenting symptoms at the time of diagnosis is listed in - Table 1. By symmetrical tumor location, the right (nondominant) side was selected in 55 patients (90\%), whereas six patients (10\%) underwent surgery on the left side.

The operative technique has been presented in our previous publications (-Fig. 1). ${ }^{14,15}$ In summary, we typically perform a trephination behind the external orbital process, just above and superior to the pterion, as for a typical pterional craniotomy. The craniotomy is extended frontally, taking care not to open the frontal sinus. The greater wing of the sphenoid is drilled extradurally in a standard fashion. After opening the dura, the sylvian fissure is proximally dissected and the internal carotid artery (ICA), as well as the neighboring neurovascular structures, are identified. Thus, the relevant important anatomic structures, such as the ipsilateral ICA, middle cerebral artery (MCA), anterior cerebral artery (ACA), and the optic nerve have already been identified in these initial steps of the operation. Dissection begins at the posterolateral and posterior tumor parts, leading to an early decompression of the ACA, the optic nerves, and chiasm. Subsequently, the tumor nidus sitting on the sphenoid plane is devascularized. Care should be taken not to open the ethmoidal air cells during this step of the procedure, to prevent postoperative cerebrospinal fluid (CSF) leakage. Hemorrhage is controlled with bipolar coagulation, oxidized cellulose, and the high-speed diamond drill. To address the contralateral tumor bulk, partial resection of the falx and crista galli is performed. At this point the inferior sagittal sinus is usually hypoplastic or absent, and hemostasis is fairly easy. The superior tumor parts are gently pulled downwards and removed. At this time, the contralateral ACA is gently dissected away from the caudolateral tumor borders. The rest of the tumor mass is dissected along the arachnoidal plane and removed.

Follow-up was done at 3 and 12 months postoperatively by means of a magnetic resonance imaging (MRI) or computed tomography (CT) scan with contrast medium and at yearly intervals after that. Patients were considered to have a recurrence if their studies verified a mass effect in spite of a complete surgical removal. Mean overall follow-up time was 122 months (8 to 239 months).

Additionally, we reviewed the international literature for case series reporting outcomes after treatment of olfactory groove meningiomas, regardless of the operative approach.

\section{Results/Summary of Cases}

Complete tumor removal (Simpson grades I or II) was achieved in 60 patients (98.3\%). Subtotal removal (Simpson grade III) was attained in one patient with recurrent tumor. In this case there was extensive tumor expansion into the ethmoidal air cells. The mean hospital stay was 18 days (6 to 125 days) and dependent on tumor size and comorbid 

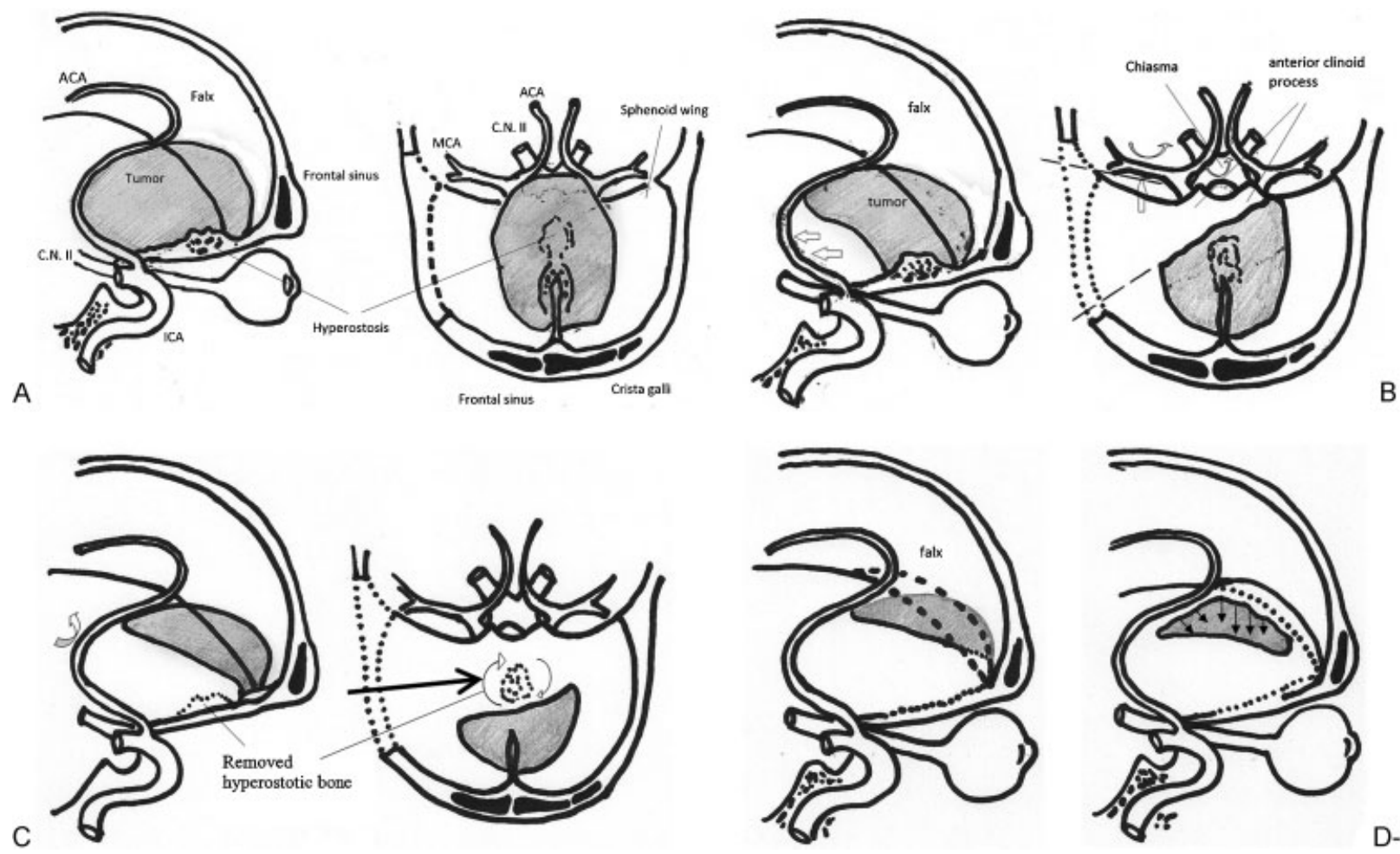

Fig. 1 (A) Typical olfactory groove meningioma. Note the close proximity of the posterior tumor border to the neurovascular complex. The pterional craniotomy extends from the lateral part of the greater sphenoid wing to the lateral frontal skull base (dotted line). The frontal sinus remains intact. (B) The posterior tumor surface is addressed first (white arrows); this allows early dissection of the middle cerebral (MCA), anterior cerebral (ACA), internal carotid artery (ICA), and optic nerves/chiasm (CN II) (curved arrows). With the crucial structures out of harm's way, the posterior tumor parts are debulked. On the right: dotted line denotes operative line of sight. The angle in the diagram is exaggerated since retraction during operation is not as extensive as in the diagram, although after extraction of a great tumor the sight can be so extensive without brain retraction. (C) Tumor hollowing continues anteriorly; the tumor nidus is devascularized and hyperostotic bone is drilled away. Diamond drill and bone wax is used to control the hemorrhage. (D) The crista galli is removed and the falx is incised (dotted line); this enables access to the contralateral tumor parts. (E) The final step of the procedures addresses the contralateral tumor borders. The tumor is gently pulled downwards and inwards. The contralateral ACA is dissected away (curved arrow).

conditions of patients. Tumor removal led to improvement of the pre-existing visual deficits in 18 out of 22 patients, with one patient demonstrating postoperative visual decline.

The overall morbidity and mortality rate was $26 \%$ and $1.6 \%$ respectively. - Table 2 demonstrates the postoperative complications recorded. The most common were epileptic seizures, occurring in 5 patients (8.2\%), followed by subcutaneous CSF collection ( 3 patients, $5 \%$ ), postoperative CSF leak (2 patients, 3.2\%), and subdural hematoma (2 patients). CSF leak was treated initially unsuccessfully with a lumbar drain; eventually, however, both patients had to undergo operative skull-base reconstruction for dural closure. This was achieved through the initial operative corridor. The two cases of subdural hematomas were treated conservatively, without any neurologic sequelae. Subdural CSF collections were treated effectively with a pressure bandage or a lumbar drain. There was one death, occurring at the third postoperative day owing to pulmonary embolism. If one takes into account the surgery-related complications only, the overall morbidity and mortality drop to $23 \%$ and $0 \%$, respectively.

In regard to the histological diagnosis, the overwhelming majority of the tumors (90\%) were classified as WHO I. There were three cases of a WHO II meningioma and two cases of an anaplastic tumor (WHO III). One tumor was characterized as a fibrohistiocytoma. Notably, two of our three recurrent cases were grades higher than WHO I, one being grade II and one grade III.

During the follow-up period, we recorded three tumor recurrences. These were detected in the context of the planned follow-up imaging, were asymptomatic, and occurred at the second, fifth, and sixth follow-up year, respectively. Expectably, these recurrences involved atypical (grade II, two patients) or anaplastic (grade III, one patient) tumors. One patient was diagnosed with a glioblastoma at a location adjacent to the operation site 9 years after the initial surgery, without having received postoperative radiation treatment.

\section{Discussion}

Olfactory groove meningiomas continue to pose a neurosurgical challenge, owing to the close anatomical relationship with vital neurovascular structures, their high vascularization, and tendency to invade the skull base sinuses, along with the fact that they have usually reached a large size at the time of diagnosis. The evolution of surgical strategies applied mirrors 
100 Surgery of Olfactory Groove Meningiomas Bitter et al.

Table 2 Morbidity, Mortality, and Tumor Recurrence in our Series of 61 Patients

\begin{tabular}{|l|l|l|}
\hline \multicolumn{2}{|c|}{ Complication } & Number of patients $(N=61)$ \\
\hline \multirow{3}{*}{ Surgical } & Seroma & $3(4.9 \%)$ \\
\cline { 2 - 3 } & Epileptic seizures & $5(8.2 \%)$ \\
\cline { 2 - 3 } & Subdural hematoma & $2(3.3 \%)$ \\
\cline { 2 - 3 } & Cerebrospinal fluid leak & $2(3.3 \%)$ \\
\cline { 2 - 3 } & Visual loss & $1(1.6 \%)$ \\
\cline { 2 - 3 } & Hydrocephalus & $1(1.6 \%)$ \\
\hline Nonsurgical & Pulmonary embolism & $1(1.6 \%)$ \\
\cline { 2 - 3 } & Pneumonia & $1(1.6 \%)$ \\
\hline \multicolumn{2}{|l}{ Mortality } & Number of patients (N=61) \\
\hline Surgical & $0(0 \%)$ \\
\hline Nonsurgical & Pulmonary embolism & $1(1.6 \%)$ \\
\hline \multicolumn{2}{|l|}{} & $3(4.9 \%)$ \\
\hline
\end{tabular}

the progress of the available microsurgical techniques; at the same time, it reflects their inherent shortcomings.

The classic subfrontal approach for olfactory groove meningiomas, introduced by Seeger, is undeniably one of the most commonly used. It usually involves a bifrontal craniotomy, elevation of the frontal lobes, and incision of the falx attachment on the crista galli. This technique allows for early devascularization of the tumor but addresses the crucial posterior neurovascular elements at the end of the proce- dure. $^{37}$ Kempe acknowledges the importance of the early identification of the optic nerve and its neighboring arteries and proposes a unilateral frontal craniotomy, beginning at the midline and extending temporally. ${ }^{38,39}$ The pterional craniotomy proposed herein combines the advantage of early tumor devascularization, as in Seeger's method, with the benefits of early exposure of the dorsal neurovascular structures. ${ }^{16}$ In the pterional approach, the optic nerve, ICA, and ACA are identified and dissected from the tumor borders at the

Table 3 Comparison of Recurrence and Mortality Rates of Various Retrospective Studies According to Operative Technique

\begin{tabular}{|c|c|c|c|c|c|c|}
\hline Authors & Technique & $\begin{array}{l}\text { Patients } \\
\text { (N) }\end{array}$ & $\begin{array}{l}\text { Percentage }(\%) \text { of } \\
\text { complete resection }\end{array}$ & $\begin{array}{l}\text { Follow-up } \\
\text { (Years) }\end{array}$ & $\begin{array}{l}\text { Recurrence } \\
\text { rate (\%) }\end{array}$ & Mortality \\
\hline Mayfrank et al, $1996^{9}$ & Interhemispheric & 18 & $18(100 \%)$ & NA & NA & $0(0 \%)$ \\
\hline Paterniti et al, $1999^{30}$ & Pterional & 20 & $20(100 \%)$ & $1-21$ & $0(0 \%)$ & $2(10 \%)$ \\
\hline Tsikoudas et al,1999 ${ }^{16}$ & Bifrontal & 13 & NA & NA & $4(31 \%)$ & $2(15 \%)$ \\
\hline Turazzi et al, $1999^{26}$ & Pterional & 37 & 37 (100\%) & $4(1-8)$ & $0(0 \%)$ & $1(2.7 \%)$ \\
\hline Hentschel et al, $2003^{19}$ & Bifrontal & 13 & $11(85 \%)$ & $2(0-5)$ & $0(0 \%)$ & $0(0 \%)$ \\
\hline Hassler et al, $1989^{4}$ & Pterional & 11 & $11(100 \%)$ & NA & $0(0 \%)$ & $0(0 \%)$ \\
\hline Schaller et al, $1994^{24}$ & Pterional & 28 & $27(96.4 \%)$ & NA & $0(0 \%)$ & $0(0 \%)$ \\
\hline Spektor et al, $2005^{25}$ & Orbitozygomatic & 7 & $7(100 \%)$ & $0-13.6$ & $0(0 \%)$ & $0(0 \%)$ \\
\hline Spektor et al, $2005^{25}$ & Bifrontal & 31 & $27(75 \%)$ & $0-13.6$ & $0(0 \%)$ & $1(3.2 \%)$ \\
\hline Spektor et al, $2005^{25}$ & Unifrontal & 7 & $5(71,4 \%)$ & $0-13.6$ & $0(0 \%)$ & $0(0 \%)$ \\
\hline Spektor et al, $2005^{25}$ & Pterional & 15 & $13(80 \%)$ & $0-13,6$ & $0(0 \%)$ & $0(0 \%)$ \\
\hline Gazzeri et al ${ }^{18}$ & Bifrontal & 35 & $31(88,6 \%)$ & $9(3-16)$ & $1(2,9 \%)$ & $1(2,9 \%)$ \\
\hline Romani et $\mathrm{al}^{23}$ & Supraorbital & 66 & $60(91 \%)$ & $0-10$ & $6(9.1 \%)$ & $0(0 \%)$ \\
\hline Nakamura et al ${ }^{21}$ & Unifrontal & 36 & $36(100 \%)$ & $4-15$ & $0(0 \%)$ & $0(0 \%)$ \\
\hline Nakamura et al ${ }^{21}$ & Bifrontal & 46 & $46(100 \%)$ & $4-15$ & $4(8.7 \%)$ & $4(8.7 \%)$ \\
\hline 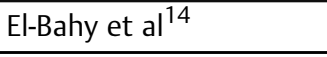 & Unifrontal & 18 & $14(77.8 \%)$ & NA & NA & $1(5.6 \%)$ \\
\hline Mirimanoff et al ${ }^{20}$ & Bifrontal & 22 & 17 (77.3\%) & 5 & $7(30 \%)$ & NA \\
\hline Obeid et $\mathrm{al}^{22}$ & Supraorbital & 15 & $15(100 \%)$ & $3.7(1-7,3)$ & $0(0 \%)$ & $0(0 \%)$ \\
\hline Bitter et al & Pterional & 61 & $61(100 \%)$ & $10(1-20)$ & $3(4.9 \%)$ & $1(1.6 \%)$ \\
\hline
\end{tabular}


beginning, at a minimal distance from the site of the craniotomy and at a time point when the surgeon is not yet exhausted from a lengthy procedure. The craniotomy involves the pterion and the lateral frontal bone; consequently, it spares the frontal sinus and enables early drainage of CSF from the carotid and prechiasmatic cisterns, thereby facilitating adequate brain relaxation. Two further advantages of the pterional approach deserve mention: first, brain retraction is usually minimal and unilateral, typically involving the frontal lobe of the nondominant hemisphere. Consequently, venous congestion and subsequent intraoperative brain edema are reduced. Second, the craniotomy itself is large enough to accommodate the tumor-associated parenchymal edema or the brain edema that may arise intraoperatively.

The ratio of recurrence after olfactory meningioma surgery varies between the different series, ranging from 0 to 31\% (- Table 3). ${ }^{9,14,16-26}$ In these series, the follow-up period ranges from 1 to 25 years. Expectably, series with shorter follow-up time report significantly reduced recurrence rates. ${ }^{17,22,23}$ In contrast, higher recurrence rates of up to $41 \%$ are associated with longer follow-up periods. ${ }^{15,16}$ In our series of 61 patients, we recorded three recurrences, corresponding to a rate of $4.9 \%$. Mirimanoff et al came to the conclusion that, apart from tumor histology, the extent of resection and its localization are decisive factors in tumor recurrence. $^{20}$ This has been confirmed in many series since. ${ }^{9,20,22}$ Regarding olfactory meningiomas in particular, the presence of tumor remnants within the ethmoidal cells seems to be the most likely etiology for tumor recurrence. ${ }^{2,9,22,27}$ To deal with this, many neurosurgeons perform coagulation of the tumor base and removal of the hyperostosis with the diamond burr. ${ }^{4,22,24,28}$ Others will aggressively remove all tumor-infiltrated bone structures. ${ }^{15,22}$ We would typically remove the tumor, meticulously coagulate its base and remove the hyperostosis with the diamond burr. Autologous fat or galeal graft plus wax and fibrin glue were used to seal the air cells and prevent postoperative CSF leak. From the available literature, we compared the various surgical approaches in regard to recurrence rate (-Table $\mathbf{3}$ ). As the normal distribution of the reported samples could not be verified, we utilized a unilateral U-test (Wilcoxon-MannWhitney test, SPSS v.13.0) for statistical evaluation. The overall recurrence ratio of $3.4 \%$ of the pterional approach (146 patient reports in total) was lower than the overall rate of the other approaches combined (8.1\% in 331 patient reports), and this difference was statistically significant $(p<0.05)$. Despite the inherent shortcomings of such a comparison, our analysis supports the notion that the pterional approach may be superior to other common approaches in regard to tumor recurrence. Undeniably, other approaches such as the extended frontal (transbasal) approach may have a greater potential in addressing frontal skull base infiltration, at the cost, however, of greater surgical morbidity. ${ }^{29}$ Our overall morbidity and mortality rate of $26 \%$ and $1.6 \%$, respectively, compare favorably to the relevant rates reported in the literature (-Table 3). ${ }^{9,14,18,19,21-27,30}$ The reported overall mortality rate $(2 \%)$ of the pterional approach is significantly lower ( $p<0.05$, Wilcoxon-Mann-Whitney test, SPSS v.13.0) than the relevant rate of $8 \%$ of the various frontal approaches. This may be associated with the potential advantage of the pterional approach in dealing with the crucial neurovascular structures.

In comparison with the "workhorse" in removal of olfactory groove meningiomas, namely the subfrontal approach, the pterional approach has distinct benefits that have previously been mentioned. Our opinion is that the advantages of the subfrontal approach are that it is usually large enough to accommodate the occurrence of brain edema, it facilitates the harvesting of a large fascia graft for frontal skull base reconstruction, and it is familiar to most neurosurgeons. The intrahemispheric surgical corridor has the advantage of utilizing a "natural," pre-existing path that allows a better tolerated brain retraction. Nevertheless, this approach also suffers from late exposure of the critical neurovascular structures. The supraorbital keyhole approach has undeniable cosmetic advantages; conversely, it necessitates opening the frontal sinus and ultimately working on the vital vessels and nerves at a final stage, through a small corridor. Endoscopic procedures are gaining popularity with the premise of offering a direct and immediate exposure to the tumor while obviating the need for brain retraction and manipulation of the neurovascular structures. $^{22,31-33}$ This approach seems to be advantageous in removing tumors that have extended in the paranasal sinuses. ${ }^{32}$ Apart from the high learning curve of the endoscopic techniques, it is also acknowledged that extracapsular dissection of the tumor from the frontal lobes and neurovascular structures needs to be done using conventional bimanual microsurgical techniques at a late operative phase. ${ }^{32}$ The removal of olfactory meningiomas through the transnasal endoscopic approach is still limited to case reports and small case series, and therefore larger studies should be awaited for a comprehensive evaluation of this technique. ${ }^{34-36}$

\section{Conclusions}

The pterional approach appears to be an excellent solution for the treatment of olfactory groove meningiomas, attaining results comparable, if not superior, to the more commonly used subfrontal techniques. Its foremost advantage is the early and direct visualization of the posterior neurovascular complex. Moreover, it allows preservation of the frontal sinus and timely tumor devascularization while avoiding excessive brain retraction and subsequent venous congestion. The pterional view is familiar to most neurosurgeons and therefore the transition to this technique is fairly straightforward. Extended transbasal techniques are associated with higher morbidity, but their role is unquestioned in cases of extensive skull base infiltration. Endoscopic endonasal approaches do appear promising, especially in cases of tumor expansion into the paranasal sinuses. Their potential limitations have already been acknowledged, but one should await the upcoming larger, long-term studies. The neurosurgeon should be aware of the armamentarium at his disposal in treating olfactory groove meningiomas and select the most appropriate technique-or their combination-on a case-by-case basis. 


\section{Financial Disclosure/Conflict of Interest}

None.

\section{References}

1 Aguiar PH, Tahara A, Almeida AN, et al. Olfactory groove meningiomas: approaches and complications. J Clin Neurosci 2009;16: 1168-1173

2 Yamashita J, Handa H, Iwaki K, Abe M. Recurrence of intracranial meningiomas, with special reference to radiotherapy. Surg Neurol 1980;14:33-40

3 Bakay L. Olfactory meningiomas. The missed diagnosis. JAMA 1984;251:53-55

4 Hassler W, Zentner J. Pterional approach for surgical treatment of olfactory groove meningiomas. Neurosurgery 1989;25:942-945, discussion 945-947

5 Fatemi N, Dusick JR, de Paiva Neto MA, Malkasian D, Kelly DF. Endonasal versus supraorbital keyhole removal of craniopharyngiomas and tuberculum sellae meningiomas. Neurosurgery 2009;64(5, Suppl 2):269-284, discussion 284-286

6 Reisch R, Perneczky A. Ten-year experience with the supraorbital subfrontal approach through an eyebrow skin incision. Neurosurgery 2005;57(4, Suppl):242-255, discussion 242-255

7 van Lindert EJ, Grotenhuis JA. The combined supraorbital keyholeendoscopic endonasal transsphenoidal approach to sellar, perisellar and frontal skull base tumors: surgical technique. Minim Invasive Neurosurg 2009;52:281-286

8 Figueiredo EG, Deshmukh V, Nakaji P, et al. An anatomical evaluation of the mini-supraorbital approach and comparison with standard craniotomies. Neurosurgery 2006;59(4, Suppl 2): ONS212-ONS220, discussion ONS220

9 Mayfrank L, Gilsbach JM. Interhemispheric approach for microsurgical removal of olfactory groove meningiomas. $\mathrm{Br} \mathrm{J}$ Neurosurg 1996;10:541-545

10 van Lindert E, Perneczky A, Fries G, Pierangeli E. The supraorbital keyhole approach to supratentorial aneurysms: concept and technique. Surg Neurol 1998;49:481-489, discussion 489-490

11 Arita N, Mori S, Sano M, et al. Surgical treatment of tumors in the anterior skull base using the transbasal approach. Neurosurgery 1989;24:379-384

12 Dave SP, Bared A, Casiano RR. Surgical outcomes and safety of transnasal endoscopic resection for anterior skull tumors. Otolaryngol Head Neck Surg 2007;136:920-927

13 van Furth WR, Agur AM, Woolridge N, Cusimano MD. The orbitozygomatic approach. Neurosurgery 2006;58(1, Suppl):ONS103ONS107, discussion ONS103-ONS107

14 El-Bahy K. Validity of the frontolateral approach as a minimally invasive corridor for olfactory groove meningiomas. Acta Neurochir (Wien) 2009;151:1197-1205

15 Solero CL, Giombini S, Morello G. Suprasellar and olfactory meningiomas. Report on a series of 153 personal cases. Acta Neurochir (Wien) 1983;67:181-194

16 Tsikoudas A, Martin-Hirsch DP. Olfactory groove meningiomas. Clin Otolaryngol Allied Sci 1999;24:507-509

17 Bassiouni H, Asgari S, Stolke D. Olfactory groove meningiomas: functional outcome in a series treated microsurgically. Acta Neurochir (Wien) 2007;149:109-121, discussion 121

18 Gazzeri R, Galarza M, Gazzeri G. Giant olfactory groove meningioma: ophthalmological and cognitive outcome after bifrontal microsurgical approach. Acta Neurochir (Wien) 2008;150:11171125, discussion 1126
19 Hentschel SJ, DeMonte F. Olfactory groove meningiomas. Neurosurg Focus 2003;14:e4

20 Mirimanoff RO, Dosoretz DE, Linggood RM, Ojemann RG, Martuza RL. Meningioma: analysis of recurrence and progression following neurosurgical resection. J Neurosurg 1985;62:18-24

21 Nakamura M, Struck M, Roser F, Vorkapic P, Samii M. Olfactory groove meningiomas: clinical outcome and recurrence rates after tumor removal through the frontolateral and bifrontal approach. Neurosurgery 2008;62(6, Suppl 3):1224-1232

22 Obeid F, Al-Mefty 0 . Recurrence of olfactory groove meningiomas. Neurosurgery 2003;53:534-542, discussion 542-543

23 Romani R, Lehecka M, Gaal E, et al. Lateral supraorbital approach applied to olfactory groove meningiomas: experience with 66 consecutive patients. Neurosurgery 2009;65:39-52, discussion 52-53

24 Schaller C, Rohde V, Hassler W. Microsurgical Removal of Olfactory Groove Meningiomas via the Pterional Approach. Skull Base Surg 1994;4:189-192

25 Spektor S, Valarezo J, Fliss DM, et al. Olfactory groove meningiomas from neurosurgical and ear, nose, and throat perspectives: approaches, techniques, and outcomes. Neurosurgery 2005;57(4, Suppl):268-280, discussion 268-280

26 Turazzi S, Cristofori L, Gambin R, Bricolo A. The pterional approach for the microsurgical removal of olfactory groove meningiomas. Neurosurgery 1999;45:821-825, discussion 825-826

27 Maiuri F, Salzano FA, Motta S, Colella G, Sardo L. Olfactory groove meningioma with paranasal sinus and nasal cavity extension: removal by combined subfrontal and nasal approach. J Craniomaxillofac Surg 1998;26:314-317

28 El Gindi S. Olfactory groove meningioma: surgical techniques and pitfalls. Surg Neurol 2000;54:415-417

29 Sekhar LN, Nanda A, Sen CN, Snyderman CN, Janecka IP. The extended frontal approach to tumors of the anterior, middle, and posterior skull base. J Neurosurg 1992;76:198-206

30 Paterniti S, Fiore P, Levita A, La Camera A, Cambria S. Basal meningiomas. A retrospective study of 139 surgical cases. J Neurosurg Sci 1999;43:107-113, discussion 113-114

31 de Divitiis E, Esposito F, Cappabianca P, Cavallo LM, de Divitiis O, Esposito I. Endoscopic transnasal resection of anterior cranial fossa meningiomas. Neurosurg Focus 2008;25:E8

32 Liu JK, Christiano LD, Patel SK, Tubbs RS, Eloy JA. Surgical nuances for removal of olfactory groove meningiomas using the endoscopic endonasal transcribriform approach. Neurosurg Focus 2011;30:E3

33 Rachinger W, Grau S, Tonn JC. Different microsurgical approaches to meningiomas of the anterior cranial base. Acta Neurochir (Wien) 2010;152:931-939

34 Fernandez-Miranda JC, Gardner PA, Prevedello DM, Kassam AB. Expanded endonasal approach for olfactory groove meningioma. Acta Neurochir (Wien) 2009;151:287-288, author reply 289-290

35 Gardner PA, Kassam AB, Thomas A, et al. Endoscopic endonasal resection of anterior cranial base meningiomas. Neurosurgery 2008;63:36-52, discussion 52-54

36 Webb-Myers R, Wormald PJ, Brophy B. An endoscopic endonasal technique for resection of olfactory groove meningioma. J Clin Neurosci 2008;15:451-455

37 Seeger W. Frontobasal operations. In: Microsurgery of the Cranial Base. Berlin: Springer-Verlag; 1983:200-269

38 Kemp LG, VanderArk GD. Anterior communicating artery aneurysms. Gyrus rectus approach. Neurochirurgia (Stuttg) 1971;14: 63-70

39 Krekorian EA, Kempe LG. The combined otolaryngologyneurosurgery approach to extensive benign tumors. Laryngoscope 1969;79:2086-2103 